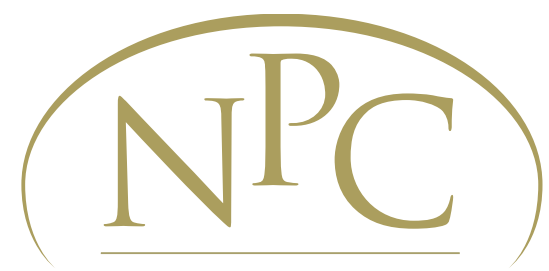

NATIONAL POVERTY

CENTER

National Poverty Center Working Paper Series

\#10-03

April 2010

\title{
Making the 1996 Welfare Reform Work: The Promise of a Job
}

\author{
Anthony J. Mallon, Virginia Commonwealth University and Guy V. G. Stevens, Federal \\ Reserve Board (ret.)
}

This paper is available online at the National Poverty Center Working Paper Series index at: http://www.npc.umich.edu/publications/working_papers/ 
MAKING THE 1996 WELFARE REFORM WORK: THE PROMISE OF A JOB

Anthony J. Mallon, Virginia Commonwealth University

Guy V.G. Stevens, Senior Economist, Federal Reserve Board (ret.)

This project was started while Stevens was a Visiting Scholar and Mallon a Research Associate at the National Poverty Center, Gerald R. Ford School of Public Policy, University of Michigan. Mallon is now an Assistant Professor of Social Work at Virginia Commonwealth University. The authors would like to thank Sheldon Danziger and Rebecca Blank, the Directors of the NPC at the time, and the Center's many scholars and staff members for providing an ideal environment for research and learning. For helpful comments and guidance we are especially grateful to Allegra Baider, Richard Bavier, Vee Burke, Sheldon Danziger, Alan Hershey, Clifford Johnson, Elizabeth Lower-Basch, Mike Miller, Anne Nichols-Casebolt, Demetra Nightingale, Amy Rynell, Larry Root, Arloc Sherman, David Stoesz, and Melissa Young. Of course, none of the above are responsible for the opinions and conclusions expressed in this paper; nor is the National Poverty Center, the Federal Reserve Board, or Virginia Commonwealth University. 


\begin{abstract}
While it is well known that Temporary Assistance for Needy Families (TANF) caseloads have shrunk by 50 percent or more since the passage of the 1996 welfare reform act (PRWORA), information regarding the economic circumstances and overall well-being of those who leave the welfare roles is less publicized. The extensive evidence examined in this paper presents a consistent picture: although approximately $60 \%$ of welfare leavers exited with a full-time job, within a year or two approximately half of all leavers fall into poverty. There is some evidence that the percentage living in poverty has increased for more recent leavers. These findings all date to periods prior to the recent severe economic recession.
\end{abstract}

The proximate cause of this high rate of poverty, as revealed in the data, is that welfare leavers end up working, on average, too few hours over the course of a year. Behind these low hours are the more fundamental causes of the measurable "barriers to work" limiting many leavers, and the limited supply of appropriate private-sector jobs, even during the so-called full-employment years of the late 1990s.

In a search of potential solutions to this problem, the present paper examines the results, design, and costs for a large number of transitional-job and welfare-to-work programs. Based on this examination, and proceeding on the assumption that any contemporary policy proposal must be "work-based," we propose and cost-out a program of jobs-of-last-resort, one that represents an extension and expansion of existing transitional jobs programs. The program, called Promise of a Job (POJ), addresses the two fundamental causes noted above, by including a job guarantee and by providing training and monitoring before and after the initial job placement. We are aware that such a program carries the danger of a sizable "displacement effect," and our program design tries to minimize this problem. We estimate the costs per participant and the overall costs of applying Promise of a Job to a number of relevant economic situations.

Since the focus of POJ is our attempt to correct the critical failings of PRWORA, we attempt to calculate the impact of combining POJ with TANF at two important points in time: in 2007, the most recent year for which we had adequate data, and in 1996, the first year of welfare reform. We estimate the costs and benefits for a number of scenarios, varying the eligibility requirements for POJ, the rate at which adults on TANF become participants in POJ, and the rate at which participants find a full-time private-sector job. Among the most important benefits of this composite program is the reduction of adult and, especially, children's poverty. The assumption of participants exiting TANF with a full-time job, either in the private or public sector, leads, as expected, to significant reductions in the relevant poverty rates. Interestingly, however, the reductions in poverty differ significantly between 1996 and 2007. 


\section{Introduction}

The passage of the 1996 welfare reform act - The Personal Responsibility and Work Opportunities Reconciliation Act (PRWORA) - heightened a conflict that to this day continues to haunt U.S. anti-poverty efforts: sustained employment has not been available for a large percentage of those who have left the welfare roles, despite their willingness and desire to work. The result is that half of welfare-leavers - along with their children - remain mired in poverty. ${ }^{1}$

Now in 2010, with the unemployment rate hovering at $10 \%$, millions of former fully-employed workers have joined the ranks of the poor. This cataclysm has at least moved the federal support of job creation to first place on the agendas of the President and Congress. In March the President signed into law the HIRE Act, an \$18 billion package of job-creating tax incentives along with $\$ 20$ billion in direct spending for highway and transit programs. This built on the American Recovery Act of 2009 [Baider and Lower-Basch (2009)]. Despite these positive developments, we take the President at his word when he asserted: "While this jobs bill is absolutely necessary, it's by no means enough." Not only do we need more federal support of job creation, we fear that present and future efforts will be too narrow: that programs designed to address the special needs of current and former welfare-leavers and the long-term unemployed will continue to fail to gain support.

Below we examine past efforts to promote the employment of welfare-leavers. We conclude that even in the best of times, if America wants to continue PRWORA's reliance on a work-based approach toward poverty reduction, a federally-supported program of jobs of last resort is a necessity. We develop and cost-out such a program, entitled Promise of a Job. Its structure and estimated costs are based on an examination of a large number of local and state programs of "transitional jobs" - programs that have often had impressive short-run, but limited long-term results. ${ }^{2}$

\section{The Outlook for Poverty and Joblessness in the Era of Welfare Reform}

We think that a detailed examination of the relevant historical data over the past decade will refute the notion that the anti-poverty performance of PRWORA was ever satisfactory or that, as presently structured, has the capacity to improve. By definition, if welfare reform is to succeed as a work-based anti-poverty program, those that leave the roles must, to a large extent, enter the workforce, maintain their employment, and escape from poverty. A large percentage of past leavers have demonstrated their motivation to escape poverty by leaving the roles with a jobabout $60 \%$ of them [Acs and Loprest (2001), Moffitt (2002)]. However, despite this degree of success in obtaining an initial job, almost all the evidence on welfare leavers, for whatever period is studied, shows also that the majority eventually falls below the poverty line - pulling a very large number of children down as a consequence. ${ }^{3}$ Further, it appears that, even before the onset of the current recession, the poverty outcomes for leavers were not improving - if anything, they were worsening [Bavier (2003), Loprest and Zedlewski (2006)].

Why the apparent discrepancy between the fact that $60 \%$ of welfare leavers depart with a job and the overwhelming evidence that half or more of these families eventually end up mired in poverty? It turns out that the evidence shows that each of three interlinked problems limit the number of hours clocked by the majority of leavers. 
First, a significant percentage of leavers do not work at all when they leave welfare; even though a majority of leavers exit with a job, $25 \%$ of overall leavers never hold a job during their first year off welfare [Acs and Loprest (2001), Moffitt (2002)]. Second, of the 60\% that leave with a job, a significant percentage does not work anywhere near full-time; and third, many of those that start with full time work cannot sustain it for long periods of time. Thus, data reported by Moffitt (2002) and Loprest and Zedlewski (2006) show that only 1/3 of leavers worked full-time during the 12-month period after they left welfare. Studies documenting the hours worked by people living in poverty confirm this link between low work hours and poverty [Gabe (2007), Sawhill and Thomas (2001)].

\section{Why Don't Leavers Work More?}

The previous section links the poverty of welfare-leavers to their inability to sustain full-time employment. Our contention, which we support below, is that two primary, unaddressed factors largely account for this failure: (1) the large number of measurable personal and structural 'barriers to work' experienced by substantial numbers of welfare recipients, and (2) the insufficient labor-market demand for the huge number of lower-skilled job seekers generated by the Act. We address each of these issues in turn, followed by our presentation of what needs to be done-assuming the continuation of a truly work-based safety net system.

\section{Personal Barriers to Work}

Research on job stability among TANF recipients suggests that many possess certain personal characteristics or face other measurable challenges that lead to job loss. Such factors, generally referred to as personal and structural 'barriers to work' because of their impact, include low basic skills and learning disabilities, poor understanding of workplace norms regarding lateness and absenteeism, physical or mental health problems of parent and/or dependent children, experiences of domestic violence, transportation problems, housing instability, and a lack of access to affordable quality child care [Allard \& Danziger (2003), Danziger, S., Corcoran, M., Danziger, S., \& Heflin, C.M. (2000), U.S. GAO 03-210 (December 2002)].

This research also shows that the number of barriers experienced by a welfare recipient is highly correlated with whether he or she is employed. The fundamental implication of the many studies on barriers to work is that a strategy of simply pushing welfare recipients into jobs, without identifying and helping them to resolve their barriers, is likely to result in rapid job loss, a return to TANF, and/or a disassociation from both welfare and work. Each of these outcomes implies that the affected family, including its children, will remain in poverty.

\section{Macro-economic Problems: The Unavailability of Private Sector Jobs}

Compounding the deleterious effect of personal barriers to employment is the economy's pervasive inability to generate a sufficient number of jobs to employ all of those who want and need to work. Even in the tightest labor market of the late 1990s, the American economy did not provide the number and composition of jobs needed to employ many of those leaving the welfare roles. The economy produced what can be called a natural experiment in late 1999 and early 2000 when the economic boom lowered overall national unemployment to 4\%; if the rising economic tide were ever to raise all boats adequately, this would be the time. ${ }^{4}$ However, a wealth of evidence testifies otherwise. Table 1 shows that even one of the lowest overall 
unemployment rates of $4.1 \%$ in December 1999 translated into 5.7 million officially unemployed workers; of more concern is the addition to that official total of those who had either dropped entirely out of the labor market or who were involuntarily forced to work part-time. These two latter categories add another 7.4 million workers to the total. At a time of purported "fullemployment" this total of 13.1 million workers amounted to $8.9 \%$ of the eligible workforce.

Table 1: "Real" Unemployment in December 1999

\begin{tabular}{|c|c|c|c|}
\hline $\begin{array}{l}\text { Unemployment } \\
\text { Rate }\end{array}$ & $\begin{array}{l}\text { Officially } \\
\text { Unemployed }\end{array}$ & $\begin{array}{l}\text { Involuntarily } \\
\text { Part-time or Out }\end{array}$ & Total \\
\hline Black & & & \\
\hline $\begin{array}{ll}\text { Hispanic } & 5.7 \% \\
\text { White } & 3.2 \% \\
\end{array}$ & 5.7 million & 7.4 million & 13.1 million \\
\hline
\end{tabular}

Source: CPS Publications (Jan 7, 2000). The Employment Situation: December 1999, Tables A, A2, A4, A10. Downloaded on 1/16/2009 from www.bls.consus.gov/cps/pub/empsit_1299.htm.

Moreover, Table 1 shows that the low overall unemployment rate masked uncomfortably higher rates for Blacks and Hispanics. Finally, Bartik (2001) shows a disturbing shift in this period toward higher unemployment for high school dropouts and, even, high school graduates. These data lead Bartik to calculate that, in order to raise the 1998 employment percentages of these two groups to 1979 levels, it would be necessary to generate 5 million more jobs (p.35).

Another implication of the total of 13 million unemployed and underemployed workers in the boom year of 1999 was that over 30 million Americans were at that time still in poverty including 11.5 million children [U.S. Census Bureau (2003), pp. 22 \& 28]. Moreover, we have seen above that, depending on the sample, the poverty rate of welfare leavers in 1999 and 2000 varied from the high 40s to well above 50\% [Bavier (2003), Loprest and Zedlewski (2006)].

Now, in March of 2010, the situation is truly bleak. With official unemployment persisting at nearly $10 \%$ for the past several months, we now have approximately 15 million officially unemployed, and a total of over 27 million, as in Table 1, either unemployed or involuntarily either employed part-time or out of the labor force. The unemployment rates for AfricanAmericans and Hispanics were at $16.5 \%$ and $12.6 \%$ respectively as of March 2010; and data for 2009 show that never married women were unemployed at a rate of $12.0 \% .^{5}$

To many, the existence of the above, seemingly intractable, problems of labor supply and demand comes as no surprise. At the dawn of welfare reform, in his 1996-97 lectures and subsequent book, Work and Welfare, Nobel laureate Robert Solow predicted that, without a serious program of job creation for welfare leavers, "the transformation of welfare into work is likely to be the transformation of welfare into unemployment and casual earnings so low as once to have been thought unacceptable for fellow citizens." "The first is that an adequate number of jobs for displaced welfare recipients will have to be deliberately created, either through some version of public-service employment or through the extension of substantial special incentives to the private sector (profit and nonprofit)"(p.39). His second conclusion dealt with job composition: "It would seem more useful to create an employment track that led to work habits and skills normally in demand in the service sector. This would also be a better match with the gender composition of the welfare population" (p.40). 


\section{Learning from Experience: Transitional Jobs}

The dream of the proponents of PRWORA - that forcing welfare recipients to enter the labor market and obtain a job would be sufficient to allow them to develop the skills needed to achieve long-term economic self-sufficiency - has largely been unfulfilled. Millions of those leaving welfare over the past decade have never, ever had a fulltime above-poverty job; of those that have, many have not been able to maintain their employment because of personal and/or structural "barriers to employment" or labor market failures.

In this section, we will briefly summarize the literature on a particular intervention, transitional jobs, which has primarily been targeted at 'hard-to-employ' individuals, such as long-term TANF recipients, and which, we believe, has shown promise in terms of outcomes and costs. ${ }^{7}$ We follow this discussion with a presentation of our own recommended program - one that builds on the transitional jobs model, but also involves both (1) an expanded effort to help welfare leavers obtain and keep private sector jobs; and (2) the guarantee or 'Promise of a Job' for those who cannot maintain or secure employment in the private sector.

\section{General Philosophy and Features of Past Transitional Job Programs}

Transitional Jobs programs are a post-PRWORA variation on publicly subsidized jobs programs of the past [Kirby et al. (2002), Cohen, (1998)]. According to the National Transitional Jobs Network, 'Transitional Jobs' is an employment strategy that utilizes temporary, wage-paid, real work, coupled with skill development and supportive services to transition people successfully into full-time work. ${ }^{8}$ TJ programs share a number of common core components including: orientation and assessment, job readiness/life skills training, case management/supportive services, the provision of subsidized transitional jobs, placement into unsubsidized jobs, retention support, and linkages to education/training. They are among the work activities for which TANF dollars can be used, including the recently injected $\$ 5$ billion in the 'TANF Emergency Contingency Fund," created as part of the American Recovery and Reinvestment Act of 2009 [Baider \& Lower-Basch (2009)].

The philosophy behind transitional jobs shares the "work-first" ethos behind PRWORA. However, transitional job programs also recognize the existence and deleterious implications of extensive "barriers to employment," the best such programs providing a supportive environment and direct services for participants who need individualized attention in making the transition into work. Transitional jobs programs have tended to target 'hard-to-employ' TANF recipients, those who, despite the standard work-first incentives and supports, have had difficulty exiting welfare to steady employment [Kirby et al., (2002)]. ${ }^{9}$ Such workers typically have one or more barriers to work, such as low educational attainment, lack of work experience, and substance abuse or mental health problems [Waller (2002), Kramer (January 1999)]. Where private jobs cannot be found, workers are often placed in public or nonprofit organizations, typically earning the state or federal minimum wage or slightly above, and working between 20 to 35 hours per week. Depending on the program, participants tend to remain in the transitional job from three months to a year, with the ultimate goal of obtaining unsubsidized employment in the private sector. $^{10}$

Participating work sites agree to employ transitional workers with an understanding that they will likely need more-than-average on-the-job mentoring and greater latitude, at least initially, in 
terms of performance issues. In the process, participants gain paid work experience and receive training, both of which improve their chances of finding and keeping unsubsidized employment. The flexibility built into many transitional work placements, and the intensive case management ideally provided by program staff, are designed to help participants to adapt more easily to the requirements of work and to identify and address problems as they arise.

In contrast to "work experience" or "workfare" programs implemented on a mass scale in places like New York City and Wisconsin [Turner \& Main (2001)], transitional jobs actually "replace a welfare check with a paycheck." Workers become eligible for federal, state, and local earnedincome tax credits, thus potentially allowing them to rise above the poverty line [Waller (2002)]. In addition, in most cases the transitional jobs show up in official employment records, allowing the worker to begin building eligibility for Unemployment Insurance.

Despite their impressive success in making placements into short-term jobs, even proponents of transitional jobs recognize that, because the jobs are limited in their scope and duration, the programs have been less successful in helping participants achieve long-term economic selfsufficiency [(Johnson, Rynell, \& Young (2010)]. A major problem in our view is that all programs that we have studied have placed time limits on how long someone might work in a subsidized position. Some barriers to employment may require more than a year to be overcome and, as Table 1 above indicates, even the booming economy of the 1990s did not provide enough jobs for all the welfare recipients that needed one. It seems evident, therefore, that President Clinton's original, and quickly discarded, welfare reform proposals, which included the provision of public service jobs for those who could not secure 'regular' employment, reflected a more accurate assessment of what many welfare recipients need [Clinton (1992)].

\section{Promise of a Job}

Our proposal, Promise of a Job (POJ), builds on the concept of a transitional job program and is consistent with the work-first philosophy of TANF, but also is designed to be an anti-poverty program. We argued above that TANF has failed as an anti-poverty program by not acknowledging that, even when willing, many welfare recipients cannot work enough to lift their families out of poverty. POJ therefore includes elements that address the difficulty for welfareleavers to secure and maintain private-sector employment. Being an anti-poverty program means that the wages of the jobs developed by the program will be sufficient, when combined with the EITC and Food Stamps, to lift the vast majority of participating families out of poverty. These jobs will be provided for as long as needed; however, the goal for POJ participants will be progress to more lucrative jobs in the private sector. Below we provide an outline of the model, detailing implementation issues and providing a range of estimates regarding its costs.

We recognize that there are those whose barriers are so debilitating that it is unlikely that they can maintain full-time stable employment in the private sector. It is our assumption that most of this population will have been appropriately assessed at an earlier stage, determined to be totally or partially disabled, and therefore directed toward income support programs for which they are legitimately eligible (e.g., Supplemental Security Income). The assessment phase of POJ, described below, may uncover a further small number of such ineligible participants. 
Nevertheless, we expect that many, if not most, participants in POJ would be individuals demonstrated to be 'hard to employ' (as opposed to being unable to work due to disability) because of substantial employment barriers or depressed labor market conditions; some will have approached or reached their TANF time limit. While this paper focuses on the TANF population, allowing us to develop empirically based cost estimates using welfare caseload data, we envision POJ being extended to other relevant populations - e.g. non-custodial fathers; individuals (including TANF recipients) with criminal records; single adults or youth living in areas with extreme levels of unemployment.

While recognizing that the specific details of any given POJ program will reflect local needs and circumstances, we present below a generic description of the six key elements that we believe will be needed in any POJ initiative: Recruitment/Referral; Assessment; Job Readiness Training; Job Development/Placement; Post-Employment Support/Retention Services; and Ongoing Case Management.

\section{Phase I: Recruitment/Referral}

The entry of participants into locally implemented POJ initiatives should operate in tandem with the respective TANF programs in each state. Such a linkage would represent the most efficient mechanism for referring clients who have not succeeded in obtaining or maintaining their employment, and is consistent with earlier efforts of this kind. For example, in the 18 Welfareto-Work programs evaluated and costed-out by Perez-Johnson et al. (2002) and Fraker et al. (2004), 10 of those studied had no expenses for recruitment, primarily because they had direct tie-ins to local TANF programs. For those programs with active recruitment components, the costs were modest and one-time: varying from $\$ 57$ to $\$ 562$ per participant. ${ }^{11}$

Additional sources of referrals for POJ would come from the organizations involved in the public workforce investment systems in each state, the comprehensive 'One-Stop' centers, which are funded through the Federal Workforce Investment Act (WIA). ${ }^{12}$ One-Stop Centers frequently provide services to individuals with multiple employment barriers, many of whom could benefit from participation in a POJ program. ${ }^{13}$

Phase II: Assessment, Job-Readiness Training, Job Development, Search, and Placement Despite the many activities encompassed under this phase and the widely varying approaches to their implementation, the preponderance of the evidence points toward the maintenance of the work first principle that pre-job training should be shorter rather than longer in duration. According to Michalopoulos (2004) "The group of programs with the most consistent effects on employment and earnings were employment-focused programs that allowed some welfare recipients to enroll in short-term education or training." In support of the retention of jobreadiness training, however, is the finding in the same paper that activities that involved job training, as long as it was employment focused, had the strongest impact of all programs on longterm employment. ${ }^{14}$

Of the programs studied in Fraker et al. (2004) and Perez-Johnson et al. (2002) that had participants and programs somewhat similar to POJ - e.g., Boston's W-t-W programs, Philadelphia's TWC program, and the various programs run in Yakima, Washington - the length of their Phase II varied from two weeks (TWC) to 7 weeks or more (Boston-Partners). ${ }^{15}$ 
None of this variation seemed to lead to either a higher placement rate into a transitional job (all three did quite well) or a higher rate of full-time work after two years (none did very well). ${ }^{16}$

The Phase II we advocate for POJ would last up to a month and use a 'rapid attachment' approach to connecting participants with employment, emphasizing job search and quick entry into the workforce through the development of Individual Employment Plans and the use of career workshops, job search classes, and other employment-focused activities. During this phase, in-depth assessments of participants' capacity to obtain employment in the private sector would be completed and any identified barriers addressed to the extent possible. This Phase would also serve to 'screen out' those who do not need a POJ. Participants who do not secure at least 30 hours of private or public-sector employment through their own efforts during this month would work in a POJ position for up to 30 hours per week, as detailed below.

In those programs for which we have cost data, the rough costs per participant in Phase II varied mainly because of the length of the program. ${ }^{17}$ Thus, the program run by Boston Partners had the highest estimated cost per participant $(\$ 3,330)$, but this was due to its length of 7 weeks or more; its daily cost per participant, at $\$ 95$, was in the medium range. Among the 18 programs studied by Perez-Johnson et al. (2002), daily Phase II costs ranged from a low \$39 to \$166. These figures give us the ability to roughly estimate the range of costs of this phase. At $\$ 100$ a day, the total cost of a month (four week) in Phase II would be $\$ 2000$. At a cost closer to the high end, say $\$ 150$ a day, the cost would rise to $\$ 3000$.

The transitional job programs that have been studied carefully show quite impressive results in placing participants. Recall that Moffitt (2002) and others agree that about $60 \%$ of welfareleavers depart with a job. This figure is for TANF leavers through approximately 2000. This $60 \%$ hurdle was easily matched for the 18 programs [U.S. Department of Health and Human Services (2008)]. Of the three closest in structure to our POJ, Boston was at $65 \%$ (even after a lengthy training program which undoubtedly increased attrition), Philadelphia at $74 \%$, and the various programs in Yakima, Washington at $80 \%$. Not only were the averages at or above the TANF average, but it must be emphasized that the participants in these 18 programs typically had reached or were close to reaching the TANF time limits and, on average, had more barriers to work than the general TANF population.

\section{Phase III: The Job}

The typical POJ position would require a minimum of 30 hours a week of work, with wages supported or completely covered by public funds. After 30 hours, POJ would pay for up to 10 hours per week for participation in job search and activities designed to resolve barriers to employment. Workers in POJ positions would be covered under all fair labor standards protections and be paid the Federal minimum wage. This income would be treated as wages and thus be subject to all applicable state and federal taxes. Likewise, POJ income would be treated as earned income for the purposes of the EITC and social security. At the federal minimum wage of $\$ 7.25$ an hour, our recommended gross pay for a full time 40 hour week would be $\$ 290$ a week, and $\$ 15,080$ a year. For TANF recipients, all participants fulfilling the prescribed work requirements would have their clocks stopped for the federal TANF time-limit.

The experiences of states and localities that have implemented subsidized jobs programs suggest that POJ placements would include support positions within the public sector as well as private 
nonprofit agencies and businesses. Based on, for example, Vermont's experience with subsidized employment, the most common jobs would likely be clerical, maintenance, recreation and various manual labor position with local governments, public schools and human service organizations [Johnson (1998)]. We envision that POJ positions will, similarly, involve clerical work, maintenance, light manufacturing and packaging, as well as food service and other retail services. Specific job duties would be determined by the respective employers in consultation with POJ program case managers. The workplaces themselves should reflect the real-life expectations, responsibilities, and rewards of 'regular' employees on the job, so that POJ workers experience both the benefits and challenges of working in a supportive environment with employers who understand that personal barriers may result in less than optimal performance [Johnson (1998), Strawn and Martinson (2002)].

While we argue that POJ is needed to support the employment needs for those who cannot secure and maintain private full-time employment, we recognize that the program must hold POJ participants accountable for meeting at least minimal work demands. We therefore recommend that the POJ participants who do not meet such minimal performance standards (e.g. attendance, avoiding unexcused absences or tardiness, basic job performance), and refuse to comply with case management recommendations regarding such issues, should be 'suspended' from the program for a period of time after which they can reapply. ${ }^{18}$ While we believe such mechanisms may be necessary, we also contend that such practices should be applied only after all other supportive (i.e. non-punitive) steps are taken.

Finally, we recognize that one of the primary concerns shared by both proponents and critics of program such as POJ is the potential for the displacement of regular public- or private-sector employees, either by direct replacement or by reduced hiring of new non-POJ employees. Ellwood and Welty (2000), in a comprehensive treatment of this subject, acknowledge that displacement rates have at times been quite high (up to two-thirds), but argue that the implicated programs have failed "to implement effective antidisplacement measures." They use studies of the history of CETA and its predecessor, PEP (the 1971 Public Employment Program), to illustrate their point. The PEP program and the early years of CETA had high estimated rates of displacement, probably because funds were given to state and local governments with no strings on hiring, limits on wage payments, or restrictions on job duration. By the latter years of CETA, in 1978-79, the estimates of displacement were down to 10-30\% [Adams, Cook and Maurice (1983), Nathan et. al (1981)]. Although the causal evidence is far from conclusive, the reduced displacement rates were attributed to stringent limitations on participation to those that were poor and suffering from long-term unemployment.

Our description of POJ contains a number of provisions that correspond to the restrictions found effective by Ellwood and Welty; however, the seriousness of the displacement problem compels us to consider additional measures. First, already embedded in POJ is its limitation to the longterm unemployed, whether on TANF currently or not; many of these potential participants also suffer from one or more barriers to employment. Further, the limitation of the POJ wage rate to the minimum wage should provide a strong incentive for a worker to move on to a more lucrative, non-subsidized job. 
However, we must admit that a potential invitation to displacement is the guarantee of a job as part of POJ -- and the possibility of long-run, unending wage subsidies to potential public or private employers. Although a POJ position may, under certain conditions, be given to a participant in perpetuity, a guarantee of a long-term fully subsidized job need not, and probably should not, be given to an employer. In many, if not all cases a public or private employer would be offered a subsidized position on condition that the worker would be, within a specified period, a candidate for a full-time unsubsidized job. To prevent employer dissembling, the subsidy could be decreased over time and/or be negotiated from the start at less than $100 \%$ of wages; moreover, penalties could be imposed - monetary or suspension from further participation in the POJ program - if unsubsidized job offers were not forthcoming for workers deemed acceptable by POJ evaluators. In any case, if a full-time job offer was not forthcoming after a certain period, a POJ participant would be removed from a given job and reassigned.

We anticipate that substantial numbers of participants, having developed skills and a work history, will leave POJ for higher-paying private sector employment. This progression will be facilitated by the actions of POJ case managers who will be expected to provide an essential link between welfare recipients and employers. Holzer (1999), for example, in a study of "Michigan Works" agencies, reported that employers that worked closely with such 'labor market intermediaries' frequently hired welfare recipients. It must be recognized, however, that independent of success in overcoming personal barriers to employment, the relative strength of the private sector labor market will also have a strong bearing on how quickly participants can exit POJ - or whether they will need to return to it as a result of weakening labor demand. For those who cannot obtain or maintain employment due to personal barriers even during times of sustained high demand for labor, a POJ position would be provided for as long as necessary to prevent them from becoming unemployed.

Phase IV: Services after the Initial Job Placement: Monitoring, Mediation, Retention, and Entry into 'Open Market' Employment

Despite the success among existing transitional jobs programs in placing participants into employment after a relatively short training phase, most leavers have not remained fully or even satisfactorily employed one to two years later [Fraker et al. (2004), Exhibits IV.3, p.78 and IV.13, p.83]. Although transitional job programs have been successful in placing their participants, of the 11 programs studied, only two with special characteristics had half or more of their participants working full-time two years after program entry. More typical, the percentage working full time after two years fell to $31 \%$ for programs in Boston (from an initial 65\%), to $25 \%$ in Philadelphia, and to $36 \%$ for Washington state. Even allowing for employment of any kind after two years, the percentages improved only to $41 \%, 36 \%$, and $48 \%$, respectively.

Only for two programs, in Maryland and Florida, where most participants had the advantage of starting with their own jobs, was the percentage of original workers employed full-time after two years greater than 50\%: 60\% in Maryland and 54\% in Florida. Both programs had much higher than average spending on what we denote as Phase IV services - on "post-employment followup," including mediation and on-job development services. Cost-wise, the expense of such services appears to be a worthwhile investment. Even at the relatively high intensity of postemployment services provided in the Maryland and Florida programs, the annual total cost per participant was only $\$ 1100$ for one and $\$ 1300$ for the other [Perez-Johnson et. al (2002), Figure III.4, p.40]. 


\section{Cost Summary and Comparison}

Summarizing our estimates above for the costs for a single participant in Promise of a Job, if one adds up the costs for a typical entrant who stays for the whole year, the range of costs would be the following: Phase I costs for referral and recruitment would vary between zero and $\$ 560$; Phase II costs would be between $\$ 2000$ and $\$ 3000$; eleven months (48 weeks) of transitional work in Phase III would be about $\$ 13,900$ (at the $\$ 7.25$ federal minimum wage in 2009); and Phase IV costs, involving liberal post-employment and retention services, would be between $\$ 1100$ and $\$ 1300$. Add in the estimated range of general administrative costs of $\$ 100$ to $\$ 600,{ }^{19}$ and the estimate for total gross annual costs for a participant who requires a POJ position for the full 11 months would be between $\$ 17,100$ and $\$ 19,360$. If the entrant is able to find a full-time private sector job immediately after the job readiness training and search activity in Phase II, the estimated annual cost would fall to between $\$ 3200$ and $\$ 5460$.

The above gross annual costs per participant are somewhat more detailed than those estimated by earlier researchers, but, for the most part, are basically comparable and similar. Most recent studies that we know of, e.g. Bartik (2001), Danziger and Gottschalk (1995), Papadimitriou (1999), and Wray (1997), start with a wage rate equal to or slightly below the federal minimum wage at the time and multiply this by from 2000 to 2080 annual hours (40 hours per week times 50 or 52 weeks). ${ }^{20}$ Papadimitriou (1999) and Wray (1997) arrive at an annual cost of $\$ 12,500$, Danziger and Gottschalk (p.172) at \$12,000, and Bartik at about \$13,000. Our wage cost of $\$ 13,900$ per participant is somewhat lower than it otherwise would be because, even for someone who stays in the program for the full year, the worker spends the first month in orientation and job search. In our model, other costs such as recruitment, training, administration, and postemployment services are added to wage costs and may raise overall costs as much as $\$ 5,460$, for a total about $40 \%$ higher than Bartik's estimate. Less comparable to our estimates are per worker cost data from the New Hope Project in Milwaukee, WI; there, actual overall costs were $\$ 9000$ per participant over two years - which covered some community services jobs (if needed), as well as health insurance and child care subsidies. Net costs were lower as savings from reductions in public assistance and the value of the work performed by program participants brought the two-year costs down to $\$ 7,200$ per participant [Bos et al. (1999)]..

\section{On the Potential Costs and Benefits of Promise of Job: Some Alternative Scenarios}

Promise of a Job represents our attempt to design a program that can, in principle, correct the critical failing of PRWORA - that half or more of welfare leavers fall quickly into poverty. This section examines the potential benefits and costs of some alternative scenarios that simulate the extension of POJ programs widely across the economy. Since the focus of this paper is the improvement of the performance of PRWORA, we consider the costs and benefits of implementing POJ in tandem with PRWORA at two different, but critical years: in 2007, the most recent year for which we have adequate data, and in 1996, the first year of welfare reform. The estimated costs and benefits presented below should not be taken as predictions, but rather as simulations based on the assumption of specific values for key parameters. We have presented above the available data on the value of such key variables as the percentage of welfare leavers exiting with a full-time job (60\%), but this and other parameters are undoubtedly subject to considerable variation; given this uncertainty, we will try to indicate how key results vary with changes in the basic assumptions. 
As far as costs are concerned, in addition to the costs per participant calculated above, the overall gross cost of a particular simulation will depend on the number of participants, the length of time, if any, each recruit spends in publicly-supported employment, and the degree to which employers are induced to cover a percentage of these costs. Over time, costs will vary as participants graduate to private-sector jobs, drop out of the program, and as new and returning participants are added to the program. In our estimates below, we will limit consideration to the first year of costs for the participants in each proposed program; moreover, for simplicity we will assume that all costs of a POJ job are picked up by the public sector; since this need not be so, our cost estimates for a given program will be an upper bound. More elaborate multi-year calculations, which are not attempted here, would require additional assumptions about the graduation rates, exit, and re-entry rates noted above.

Offsetting the above direct costs are a potentially wide range of increased revenues and reduced indirect costs: revenues from the productive work of the participants; increased income taxes paid; the reduction or elimination of the TANF benefits the entrant was receiving; and a long list of possible social or third-party benefits. Some of these revenues and cost savings can in principle be captured by the agency administering POJ, thus lowering the total direct costs incurred by the program. Some indirect benefits and cost savings may be impossible to capture by the administering agency, but are nevertheless potentially very large: (1) the reduction of the direct and indirect costs of physical and mental illnesses - savings that are likely because of a participant's exit from poverty and joblessness; (2) the health and other costs for children that, as mentioned above, will be reduced by an exit from poverty; (3) the multiplier effects on the economy of the increased earnings of POJ participants; and (4) the cost savings to society at large, discussed at more length below, by the demonstrably lower rates of crime and incarceration resulting from the reduction in the poverty rate and the increase in employment. When we examine the quantitative estimates of such social benefits, their magnitude overwhelms any estimate of the net private and social costs.

\section{Scenario \#1: The Costs and Benefits of Applying POJ to the 2007 TANF Caseload}

For 2007, the monthly average of "families" still on TANF - including "child-only" cases - was just under 1.7 million $(1,669,076)$. This total was divided into approximately 837,000 one-parent families, 58,000 two-parent families, and 772,000 child-only or "no parent" families. Of the 3.9 million total recipients in these families, almost 3 million were children. ${ }^{21}$

Given the size and composition of this caseload, a number of assumptions and calculations are required to determine the number of adults eligible to enter the POJ program. We will assume first that POJ would be available to the head of household in each one- and two-parent on TANF - a total of 894,000 participants. More difficult and controversial is the calculation of the potential number of adult participants from so-called child-only families; we eventually consider two alternatives. A recent study, Gibbs et al. (2004), prepared for HHS, concluded that approximately $50 \%$ of the children in child-only families lived with parents that, for various reasons, were not eligible for TANF; the other $50 \%$ lived with relatives or third parties. ${ }^{22}$ Of the half of the cases still living with parents, $42 \%$ of the parents ( $21 \%$ of the whole sample) were disabled and covered under Supplemental Security Income (SSI); the rest of the families were headed by either immigrants ineligible for TANF (32\%), parents that had been sanctioned off of TANF (10\%), or parents with "other" disqualifications $(16 \%)$. Of the $50 \%$ of child-only cases not living with a parent, the HHS study indicates that for various reasons these caretakers had too 
much income to be eligible for TANF. Following the HHS analysis, we shall assume that this second half of the child-only cases, along with the $21 \%$ of parents on SSI, had no need to participate in POJ because they were out of poverty. Putting all of this together, $29 \%$ of the child-only cases, those units headed by immigrants, sanctioned parents, and "other" cases, could be considered for POJ. In 2007, these totaled 223,800 cases. $^{23}$ If we add these politically controversial child-only cases to the estimated 894,000 eligible cases from one- and two-parent families, we reach a maximum of approximately 1.118 million adults eligible for POJ in 2007.

We calculate the costs and benefits of two alternatives for 2007: first, the "maximum" participation case assuming 1.118 eligible adults, with the further assumptions that no entrant drops out: i.e. at the end of their job training and search, each either moves on to and keeps a full-time private-sector job or accepts and keeps (for the remainder of the year) a full-time job supplied through the POJ program. Alternatively, and undoubtedly more realistically, we also consider the case where no adults from child-only families are eligible for POJ and where only, say, $80 \%$ of the remaining eligible participants enter the program ( $80 \%$ of 894,000 or 715,200$)$.

POJ promises to put all participants into a job after a relatively short training and evaluation period - either a private sector job, or a government supported job in a non-profit or government agency. Obviously the overall direct cost of POJ depends also on the percentage of the participants that will immediately take up private sector jobs after Phase II. A fairly optimistic assumption would be that the 2007 percentage would match the historical percentage of $60 \%$ (discussed above and in, e.g., Moffitt (2002)). This is probably an overestimate, however, given that those remaining on TANF in 2007 had on average more barriers to employment than earlier leavers; moreover, Bavier (2003) shows that later leavers have progressively higher rates of poverty (and presumably fewer full-time jobs) than earlier leavers. For more realism, let us therefore assume a lower percentage, say 50\%, going to private sector jobs after Phase II.

Consider, first, the maximum participation (and cost) case. Under the 50\% assumption, exactly one half of the 1.118 million eligible participants would be assumed to be able to take up fulltime private sector jobs after going through the Phase II evaluation and job readiness training; these participants would also be eligible for Phase IV retention services. Assuming the highest costs estimated above, the costs for these "early graduates" would total \$5460: \$560 for search, $\$ 3000$ for Phase II, $\$ 1300$ for Phase IV, and $\$ 600$ for administrative costs. If, however, the cost of Phase II - and the assessment, job search, and job readiness training - could be charged to the TANF program (which often does much of this type of work), then the cost to POJ of this group would be reduced by $\$ 2000$ to $\$ 3000$ per person. Taking the upper bound of $\$ 5460$, the total cost for the 559,000 early grads would be $\$ 3.1$ billion.

The other half of the participants would require a public sector transitional job - possibly for the whole year - that would add $\$ 11,150$ per participant (at the 2007 minimum wage of $\$ 5.85$ ), for a total cost for the first year of $\$ 16,610$. Adding the total cost of $\$ 9.3$ billion to the $\$ 3.1$ billion for the early grads totals $\$ 12.4$ billion as the upper bound for the "maximum" 2007 program. This upper bound could be lowered substantially - by $\$ 4260$ per participant - if one used the lower end of the costs of each Phase and assumed further that TANF paid for Phase II search and training costs; the cost for the program would then fall by $\$ 4.8$ billion to $\$ 7.6$ billion. 
The more "realistic" case - assuming no adult participants from "child-only" families, along with an $80 \%$ take up rate (rather than a $100 \%$ ) from eligible adults - leads to significantly lower costs (and benefits). The eligible number of cases would be reduced to the 894,000 heads of one- and two-parent families, and the number of POJ participants to just over 715,000. Retaining the 50\% graduation rate to private-sector jobs after Phase II, the upper bound of costs would now be $\$ 2.0$ billion for "early grads" and $\$ 5.9$ for those needing a subsidized job: a total of $\$ 7.9$ billion. If, as above, we calculate a lower bound, the total would fall by $\$ 3$ billion to $\$ 4.6$ billion.

Going from the costs to the benefits of linking POJ to the 2007 TANF, the major impact would revolve around releasing the great majority of participants from poverty. Of particular interest is the impact of our alternative simulations on the 2007 poverty rate, particularly the children's poverty rate. ${ }^{24}$ Of the 3 million children on TANF in 2007, we estimate for the maximum case that all but those in two categories would exit poverty: the 548,000 children in child-only cases that we calculated above were already be above the poverty rate; and 255,000 children from families so large that even a full-time POJ job would not raise the family above the poverty line. Thus, a net of 2.2 million children would exit poverty as a result of POJ. A similar calculation leads to an estimate of 1.13 million adults released from poverty in this case: 837,000 in oneparent and 116,000 in two-parent families, a minimum of 224,000 from poor, child-only families, minus 43,000 adults in large families with 5 or more children. ${ }^{25}$

For 2007, therefore, the implementation of the "maximum" POJ would reduce the number of people in poverty (adults plus children) by a bit more than 3.3 million (of a total of 37.3 million). The overall poverty rate would have fallen to $11.4 \%$ from $12.5 \%$ - a decline of $8.8 \%$ overall. Children's poverty would be reduced more dramatically: with 2.2 million released from poverty of an original 13.3 million poor children, the children's poverty rate would fall from the disgraceful observed rate of $18 \%$ to a still embarrassing $15 \%$, a reduction of $17 \%$ in the number of children below the poverty line.

These percentages highlight interesting facts about TANF and poverty rates in 2007. Although in this "maximum" coverage case, POJ would succeed in getting almost all children covered under TANF out of poverty, by 2007 only $18 \%$ of the 13.3 million poor children were covered by TANF. Thus, even a program that would completely eliminate poverty among TANF recipients would, by 2007 , have a fairly limited impact on overall poverty rates. Our simulation for 1996 in the next section shows that this situation was not always the case.

For the more realistic case costed-out above, the effect of POJ on poverty rates would be even less. The exclusion of adults from poor child-only families from POJ jobs would leave 224,000 more children and adults in poverty (when compared to the results of the "maximum" example). The $80 \%$ take-up rate would lower the impact on poverty reduction by another $20 \%$. In total, the number of children released from poverty would fall to 1.6 million (from 2.2); total children plus adults released would be 2.3 million. The children's poverty rate would fall to $15.8 \%$ (from $18 \%$ ) and the overall poverty rate would fall to $11.7 \%$. 
Scenario \#2: What if POJ had been added to PRWORA in 1996?

The legislative history of PRWORA is filled with calls for a federally-funded program of jobs of last resort as a component of the reform; early on, as noted above, then Presidential candidate Bill Clinton, in promising to "end welfare as we know it," espoused such a program. In the end, of course, no such program passed. What might have happened if POJ had been part of PRWORA?

As we did for Scenario \#1 above, we can estimate the number cases that would have been eligible for POJ, the number of jobs of last resort that would have been created, the overall costs, and the impact of the program on the rates of adult and children's poverty. At PRWORA's passage in 1996, a total of 4.434 million family and 978 thousand child-only cases, including a total of $81 \frac{1}{2}$ million children, were covered under AFDC. Let us consider the costs and povertyreduction effects of the "maximum" and "realistic" participation cases discussed above.

For the "maximum" case, as discussed in the last section, an adult in $29 \%$ of the 978,000 childonly cases is assumed eligible for POJ; moreover, as an upper bound we assume that $100 \%$ of eligible adults complete the $1^{\text {st }}$ year of the program. Using the same estimation method as for 2007, we calculate a total of 3.7 million adults eligible for POJ - 3.46 million AFDC heads-ofhousehold and approximately 283 thousand more adults eligible because of child-only cases.

Using the historical average of $60 \%$ discussed at length above, we estimate that 2.2 million of the 3.7 eligible adults would have graduated to a full-time private sector job after finishing the assessment and job readiness phases of POJ. The rest, 1.5 million, would participate in the full program, including 11 months of fully subsidized work during the first year.

Using the upper bound of cost estimates, the total cost for the 2.2 million not requiring a publicly-funded job would be $\$ 12.0$ billion. For the rest, the cost, at the 1996 minimum wage of $\$ 4.75$, would be $\$ 21.8$ billion, leading to a total cost for the program of $\$ 33.8$ billion. If one uses the 2009 minimum wage, scaling the totals to what costs more-or-less would be today, $\$ 7.2$ billion is added to each total above. The total cost would rise to $\$ 41.0$ billion.

Under the assumptions of this case - that participants worked full-time either in the private sector or in a transitional job - the implementation of POJ would have caused a strong, almost immediate reduction in the poverty rate. The impact would have been much stronger than calculated above for the similar program applied in 2007 . The 1996 poverty rates were $13.7 \%$ for the overall population and $20.5 \%$ for children ( 14.5 million children in poverty). POJ would have taken an estimated 4 million adults out of poverty (3.852 million adults on the AFDC roles plus the 283,600 poor adults generated by the child-only cases, minus the estimated 157 thousand adults in families with 5 or more children that would remain in poverty); in addition, 6.9 million children would rise out of poverty (all of the $81 / 2$ children under AFDC minus 694 thousand child-only cases already above the poverty line and an estimated 940 thousand children in the aforementioned large families). With a total of 10.9 million people released from poverty, the overall poverty rate would have fallen 4.1 points to $9.6 \%$, a reduction of $30 \%$. 
For children, taking almost 7 million off the poverty roles would have reduced the children's poverty rate by almost half - from $20.5 \%$ to $10.7 \%$. This would have been the lowest children's poverty rate ever recorded in the United States, over 3 points lower that the all-time low of 14\% recorded in 1969.

Let us dwell a moment on this estimated reduction in the children's poverty rate - since children's welfare is a primary raison d'etre of this article. The children's poverty rate has never come close to $10 \%$ since 1996; its low since PRWORA was $16.1 \%$ in 2000 - and all admit that a significant part of this 4.5 point reduction from 1996 was the result of the booming economy of the late 1990s. Consider what the children's poverty rate would have been reduced to in 2000 had the impact of the booming economy been added to that of POJ.

A consideration of the more realistic case introduced in the previous section shows that these dramatic reductions in the overall and children's poverty rates are not artifacts of the admittedly expansive assumptions of the "maximum" case. Assuming a more realistic $80 \%$ take-up rate and the exclusion of adults associated with child-only cases leads to an estimate of 2.77 million adults enrolled in POJ (compared with almost a million more, 3.7 million, for the previous case). Assuming, as above, a $60 \%$ graduation rate to a private-sector job after Phase II, the costs for this case would total $\$ 25.1$ billion: $\$ 9.1$ billion for the early graduates and $\$ 16$ billion for the 1.1 million participants that would require a federally supported job.

With fewer participants, fewer adults and children would be released from poverty. However, once again, poverty reduction would be much greater than for 2007 . We calculate that 2.96 million adults and 5.27 children would be released from poverty; this would lower the overall poverty rate by almost a quarter to $10.6 \%$ and the children's poverty rate by over a third from $20.5 \%$ down to $13.1 \%$. These reductions are of course less than those for the maximum case, but nevertheless, at $13 \%$, the children's poverty rate would still have reached a record low.

In the end, the dramatic reductions in poverty rates under both cases for this 1996 scenario help illuminate the causes of the more modest reductions observed for the same simulations in 2007. The fundamental cause of the difference is that a much higher percentage of the poor - especially poor children - was covered under AFDC in 1996 than under TANF in 2007. Although the total number of poor children was not dramatically higher in 1996 than in 2007 (14.5 versus 13.3 million), 54\% of these were covered under AFDC (including two-thirds of poor AfricanAmerican children), whereas only $19 \%$ of poor children were covered in 2007 under TANF. Unlike the situation in 1996, by 2007 no job program working solely through TANF would have been capable of having a dramatic impact on children's poverty.

\section{Net versus Gross Costs}

In view of the estimated cost of the banking bailout plan of more than $\$ 700$ billion, the estimated costs of the various scenarios described above may seem modest by today's standards. Even so, the net cost, after subtracting estimates of the host of offsets listed above, would be much smaller. In fact, in terms of net social costs, it is almost certain that each of our scenarios would have more than paid for itself! 
The key items in reaching this conclusion are the present-day and future social costs of having children raised in poverty - and the large monetary benefit from eliminating poverty for some or all of them. We shall treat these particular benefits, carefully estimated by Holzer et al. (2007), at the end of this section.

First, however, consider the benefits related more-or-less directly to the work effort by a POJ participant. Most obvious is the value of the production created by the new worker. Clearly, it wouldn't usually be zero, as so far assumed implicitly. What it would be depends on the value of what is produced, but also on what we assume for the alternative position: at one extreme, if no participant would have worked without POJ, then all the product is attributable to the program. Calculating the true net increase in revenue captured by the provider of the transitional job would provide a tool for the administrators of POJ to estimate how to divide the wage and other costs of the transitional worker between the program and the job-provider. Another direct benefit would be the added income and profits taxes captured by the government.

Two other sources of cost savings are objective and reasonably easy to estimate. TANF support payments can be reduced or eliminated as POJ participants move either to private sector jobs or transitional jobs. It may be that welfare administrators would want to move the federal and state TANF funds to other programs, such as child care, but they also could be eliminated or transferred to support POJ. Similarly, if the family of a POJ participant is able to climb out of poverty on the basis of its new private sector earnings alone, then there would no longer be a need for a full complement of Food Stamps and other means-tested social benefits.

A host of other social costs related to the poverty of adults in a given household - some less easily calculated than the above - would also be reduced: increased costs associated with untreated mental and physical illness; costs associated with the positive association between poverty, on one hand, and crime, family breakup, and spousal and child abuse, on the other. Insofar as TANF recipients may be collecting unemployment insurance, the reduction in these payments would also be a cost offset; this latter cost would figure more prominently if POJ was expanded to include a wider set of the unemployed.

The recent (2007) paper by Holzer, Schanzenbach, Duncan and Ludwig documents the enormity of the social costs generated by raising children in poverty. As the authors make clear in their title - Subsequent Effects of Children Growing Up Poor - their estimates incorporate costs that accumulate over the whole lifetime of a deprived child. The authors purposely provide an underestimate - a lower bound - of the future costs to society of only three of the many impacts of childhood poverty: reduced future output; increased violent crime; and the combination of increased medical costs and lower life expectancy. In total, their estimate is that childhood poverty presently is costing the nation almost $4 \%$ of gross national product - a total of $\$ 500$ billion dollars for 2007 alone. Adding the elimination of such costs to the mix would have a dramatic positive impact on the net social benefit of even a modest jobs program. Consider that for the "maximum" scenario for 2007, we calculated that 2.2 million children exited poverty, a reduction of the total number of poor children (13.3 million) by a moderate $17 \%$. Scaling Holzer et al.'s (2007) cost total, one could argue that a sustained job program of this size would save $17 \%$ of the $\$ 500$ billion annual costs of children's poverty: $\$ 85$ billion a year. Such a saving is more than 6 times the $\$ 12.4$ billion upper bound of the estimated cost of this scenario - without even considering the other cost-offsets discussed above. Although we are reluctant to apply the 
cost estimates of Holzer et al., calculated for 2007, to our simulations for 1996, we are sure that any reasonable extrapolation would also show that these 1996 programs would pay for themselves many times over.

\section{Conclusion and Summary}

A large number of studies, reviewed above, conclude that, in the decade plus since PRWORA was enacted, half or more of the people that have left welfare, including many that have left with a job, have not been able to escape from poverty; most distressing, a large number of these people were children. We have shown that such was the case even during the generally favorable economic conditions holding from 1996-2000. The most likely causes of this disappointing outcome were in our view the deficiency in the demand for labor, even at the height of the boom, and the "barriers to work" faced by the average welfare leaver. If adult and, especially, children's poverty is to be eliminated or greatly reduced, these two critical problems must be addressed much more directly by PRWORA or its successor programs.

Our recommendation for addressing both deficiencies in labor demand and "barriers to work" is a program we name Promise of a Job - a proposal designed as an extension and expansion of existing transitional job programs. We accept as a basic assumption that the American people continue to support and require that anti-poverty efforts be based on work. Thus, POJ requires consistent with PRWORA - that all but the disabled must work more-or-less full time - the "personal responsibility" part of PRWORA. But POJ also incorporates what PRWORA, despite its title, does not: that responsibility goes both ways, and that American society, using POJ, shoulders the responsibility of the "reconciliation" of "work opportunities" and personal responsibility by guaranteeing the availability of a job to everyone willing and able to work. We believe that a program containing a carefully designed job guarantee will go a long way toward solving both the macroeconomic problem of insufficient labor demand and the associated problem of providing an adequate composition of jobs.

A second necessary part of Promise of a Job, building on the best results of existing transitional job programs, is to improve the quality of the workforce leaving the welfare rolls, by reducing or eliminating "barriers to work." Here we rely and try to build on tested and, where possible, proven job readiness interventions, and on the provision of retention services while the participant is on the job. But we admit that there is much to learn in this area.

We have costed-out different versions of Promise of a Job, relating these costs to the typical annual costs per participant observed for transitional jobs programs, some of which continue to function today. We have also compared our estimates of overall costs with those of other proposals for 'employer of last resort' programs. The gross costs are not low, but are not high when compared to such "programs" as the war in Iraq and the TARP program for the financial system. Moreover, when we move to the net social costs of Promise of a Job, bringing in the cost savings from reducing or eliminating existing TANF and other poverty programs, and from eliminating a host of social costs engendered by children's poverty, our program leads invariably to large net social benefits. 
Much of this net benefit is directly or indirectly related to the reduction of poverty - adult, but particularly, children's poverty. We calculated the impact of a number scenarios or simulations: what would have happened, under varying assumptions, if a program like Promise of a Job had been instituted in 2007 (the year for which more recent data on TANF caseloads are available); or in 1996-97, in tandem with the demise of AFDC and the inception of PRWORA. The costs are calculated for the first full year of coverage for programs of varying size. Costs and benefits are calculated on the assumption that all participating adults hold full-time minimum wage jobs in either the private sector or under the job guarantee of the POJ program. On the benefit side, depending on the year and the eligibility assumptions, there are significant reductions in the relevant poverty rates. It turns out that the poverty reductions are much more dramatic for the earlier, 1996-97 period.

For the 2007 period, despite the heroic assumption that all eligible adults work full time for the year and, because of that, most affected families (except for very large ones) emerge from poverty, the maximum reduction in the overall poverty rate is 1.1 points, from an observed $12.5 \%$ to $11.4 \%$ (although 3.3 million adults and children are released from poverty). Even though almost all people still on TANF would emerge from poverty in this simulation, it turns out that such a small percentage of the overall poor were still on TANF in 2007 that the societal poverty rate would be affected only moderately.

The experiments for 1996-97 lead to very different and dramatic changes in poverty - primarily because such a large percentage of the poor were on AFDC in that period. Even for our more "realistic" or conservative simulation, 8.2 million people would have been released from poverty, including 5.3 million children. The overall poverty rate would have fallen almost a quarter from $13.7 \%$ to $10.6 \%$. The children's poverty rate would have fallen more dramatically over a third from $20.5 \%$ to $13.1 \%$. Such a rate would have been a record low for children's poverty. These results show the power of an effective job guarantee that becomes available to a significant percentage of the poor.

It should also be noted parenthetically that Promise of a Job would by its very nature be a decentralized program, with the most important action occurring at the local level. Funding is likely to come largely from the federal and state governments, but job training and search, the creation of transitional and permanent jobs, and the provision of retention services once participants are placed - the guts of the program - would all be implemented at the local level.

Given the relatively small size of Promise of a Job when compared to the 2009 Stimulus Program and to current proposals for creating jobs now being debated, it would appear easy to embed our program within the larger effort. However, we are concerned that current proposals seem to concentrate so exclusively on the recently unemployed that the population of welfareleavers and their families might be forgotten, especially when overall unemployment returns to more politically acceptable levels. 


\section{REFERENCES}

Acs, G., Loprest, P., and Roberts, T. (2001). Final Synthesis Report of Findings from ASPE "Leavers" Grants. Washington, DC: The Urban Institute.

Adams, C. F., Jr., Cook, R. F.; Maurice, A. J. (1983). "A Pooled Time-Series Analysis of the Job-Creation Impact of Public Service Employment Grants to Large Cities." Journal of Human Resources 17(2): 283-94.

Allard, S. W. and Danziger, S. (2003). "Proximity and Opportunity: How Residence and Race Affect the Employment of Welfare Recipients." Housing Policy Debate, 13 (4), 675-700.

Baider, A., and Lower-Basch, E. (2009). Making the Employment Connection: New Opportunities to Support Transitional Jobs Programs Using the TANF Emergency Contingency Fund. Washington DC: Center for Law and Social Policy.

Baider, A. and Frank, A. (May 2006). Transitional Jobs: Helping TANF Recipients with Barriers to Employment Succeed in the Labor Market. Washington DC. Center for Law and Social Policy.

Bartik, T. J. (2001). Jobs for the Poor: Can Labor Demand Policies Help? New York: Russell Sage Foundation.

Bavier, Richard (2002). "Welfare Reform Impacts in the SIPP," Monthly Labor Review XX, November: 23-38.

Bavier, R. (2003). "Notes for APPAM 2003 conference panel 'Conditions limiting work among TANF entries, stayers, and leavers.” Unpublished draft of August 26, 2003.

Bos, J. M.; Huston, A. C.; Granger, R. C.; Duncan, G. J.; Brock, T. W.; McLoyd, V. C.; Crosby, D.; Felleratch, V.; Gibson, C.; Magnuson, K.; Mistry, R.; Poglinco, S. M.; Romich, J.; and, Ventura, A. M. (April 1999). New Hope for People with Low Incomes: Two-Year Results of a Program to Reduce Poverty and Reform Welfare. New York: Manpower Demonstration Research Corporation.

Charlesworth, L., Hercik, J. M., and Kakuska, C. J. (undated). TANF Child-Only Cases Trends and Issues. Welfare Peer Technical Assistance Network (of HHS, Admin. of Children and Families, Office of Family Assistance). Downloaded on 4/21/09 from http://peerta.acf.hhs.gov/pdf/child_only.pdf.

Clinton, Governor Bill (1992). Putting People First. Mimeo.

Cohen, M. (September, 1998). Work Experience and Publicly-Funded Jobs for TANF Recipients. Welfare Information Network. Issue Notes, Vole 2, No. 12. http://www.financeproject.org/index.cfm?page=2.

Danziger, S. and Gottschalk, P. (1995). America Unequal. Cambridge, MA: Harvard. 
Danziger, S., Corcoran, M., Danziger, S., and Heflin, C.M. (2000). "Work, Income and Material Hardship After Welfare Reform.” Journal of Consumer Affairs, 34(1), 6-30.

Danziger, S., Heflin, C.M., Corcoran, M.E., Oltmans, E., \& Wang, H.C. (2002). "Does it pay to move from welfare to work?” Journal of Policy Analysis and Management, 21(4), 671-692.

Devere, Christine (2001). Welfare Reform Research: What Do We Know About Those Who Leave Welfare? Washington, DC: Congressional Research Service.

Economic Report of the President (2002). Washington, D.C.: U.S. Government Printing Office.

Ellwood, David T. and Elisabeth D. Welty (2000). "Public Service Employment and Mandatory Work: A Policy Whose Time Has Come and Gone and Come Again?" in Blank, Rebecca M. and David E. Card, eds., 299-372.

Fraker, T. M., Levy, D. M., Perez-Johnson, I., Hershey, A. M., Nightingale, D. S., Olsen, R. B., and Stapulonis, R. A. (2004). The National Evaluation of the Welfare-to-Work Grants Program: Final Report. September 2004. Washington, DC: Mathematica Policy Research, Inc.

Gabe, T. 2007. CRS Report for Congress: Trends in Welfare, Work, and the Economic WellBeing of Female-Headed Families with Children: 1987-2005. Washington, D.C.: Congressional Research Service (Order Code RL30797, Updated March 29, 2007).

Gibbs, D., Kasten, J., Bir, A., and Hoover, S. (2004). Children in Temporary Assistance for Needy Families (TANF) Child-Only Cases with Relative Caregivers: Final Report. Research Triangle Park, NC: RTI International (RTI Project \# 07147.018) for ASPE, U.S. Department of Health and Human Services.

Harvey, P. (1989). Securing the Right to Employment: Social Welfare Policy and the Unemployed in the United States. Princeton NJ: Princeton University Press.

Holzer, H. J. (1999). "Will Employers Hire Welfare Recipients? Recent Survey Evidence From Michigan." Journal of Policy Analysis and Management, 18(3), 449-472.

Holzer, H. J., Schanzenbach, D. W., Duncan, G. J., and Ludwig, J. (Jan. 24, 2007). The Economic Costs of Poverty in the United States: Subsequent Effects of Children Growing Up Poor. Washington, DC: Center for American Progress.

Johnson, C. (1998). Publicly-Funded Jobs For Hard-to-Employ Welfare Recipients. Washington DC: Center for Budget and Policy Priorities.

Johnson, C., Rynell, A., and Young, M.(2010). Publicly Funded Jobs: An Essential Strategy for Reducing Poverty and Economic Distress Throughout the Business Cycle. Washington DC: The Urban Institute.

Kirby, G.; Hill, H.; Pavetti, L; Jacobson, J.; Derr, M.; and Winston, P. (April 2002). Transitional Jobs: Stepping Stones to Unsubsidized Employment. Washington, DC: Mathematica Policy

Research, Inc. 
Kramer, F. (January 1999). Serving Welfare Recipients with Disabilities. Welfare Information Network Vol. 3, No. 4. http://www.financeproject.org/index.cfm?page=2.

Loprest, P. and Zedlewski, S. (2006). The Changing Role of Welfare in the Lives of Low-Income Families with Children. Occasional Paper Number 73. Washington, DC: The Urban Institute.

Meyer, Daniel R., and Maria Cancian (2001). "Executive Summary of Volume II: The WellBeing of W-2 Families," In W-2 Child Support Demonstration Evaluation Phase I: Final Report, Daniel R. Meyers and Maria Cancian, principal investigators, Madison, WI: Institute for Research on Poverty.

Michalopoulos, C. (March, 2004). What Works Best for Whom: Effects of Welfare and Work Policies by Subgroup. New York: Manpower Demonstration Research Corp.

Moffitt, R. A. (2002). From Welfare to Work: What the Evidence Shows. WR\&B Policy Brief \#13. Washington, DC: The Brookings Institution.

Nathan, R. P.; Cook, R. F.; Rawlins, V. L. (1981). Public Service Employment: A field Evaluation. Washington, DC: Brookings.

National Transitional Jobs Network. www.transitionaljobs.net

Papadimitriou, D. (1999). "No Cheers for Full Employment." Challenge 42, no.6 (NovemberDecember): 80-102.

Perez-Johnson, I., Strong, D., Van Noy, M., and Nagatoshi, C. (2002). Understanding the Costs of the DOL Welfare-to-Work Grants Programs: Final Report. Princeton, NJ: Mathematica Policy Research, Inc.

Renwick, T. (2008). Transitional Jobs Return On Investment Study. New York: Fiscal Policy Institute.

Sawhill, I. V., and Thomas, A. (2001). A Hand Up for the Bottom Third: Toward an Agenda for Low-Income Families. Working Paper, Brookings Children's Roundtable, May 2001.

Washington, DC: Brookings.

Smith, D. and Woodbury, S. (1999). "The Low-Wage Labor Markets: The Business Cycle and Regional Differences" in The Low-Wage Labor Market: Challenges and Opportunities for Economic Self-Sufficiency. Washington, D.C.: The Urban Institute.

Solow, Robert M. (1998). Work and Welfare. Princeton, NJ: Princeton University Press.

Stevens, Guy V.G. (2002). "Welfare Reform and the Well-Being of America's Children." Challenge 45, no. 1 (January-February): 6-46.

Strawn, J. and Martinson, K. (June 2002). Steady Work and Better Jobs: How to Help LowIncome Parents Sustain Employment and Advance in the Workforce. New York, NY: Manpower Demonstration Research Corporation. 
Swartz, R, Kauff, J., Nixon, L, Fraker, T., Hein, J., and Mitchell, S. (1999). Where Did Families Go When AFDC Ended in Milwaukee? New York: Mathematica Policy Research and the Hudson Institute.

Turner, J. and Main, T. (2001). "Work Experience under Welfare Reform.” In, Blank, Rebecca and Ron Haskins, eds. The New World of Welfare. Washington DC: Brookings.

U.S. Census Bureau (September, 2003). Poverty in the United States: 2002. Washington, DC.

U.S. Department of Health and Human Services, Administration for Children and Families (2008). Downloaded 9/11/2008 from: www.acf.hhs.gov/programs/ofa/datareports/caseloard/2007.

U.S. Department of Health and Human Services, Administration for Children and Families (2009) etc see endnote 22.

U.S. General Accounting Office, GAO-03-210. (2002, December). Former TANF recipients with impairments less likely to be employed and more likely to receive federal support. Washington, D.C. http://www.gao.gov/new.items/d03210.pdf

U.S. House of Representatives, Committee on Ways and Means (1998). 1998 Greenbook. Washington, D.C.: U.S. Government Printing Office.

Waller, M. (May 2002). Transitional Jobs: A Next Step in Welfare to Work Policy. Washington, DC: The Urban Institute.

Wray, L. R. (1997). Government as Employer of Last Resort: Full Employment Without Inflation. Working Paper no. 213. Annandale-on-Hudson, NY: The Levy Economics Institute, Bard College. 


\title{
ENDNOTES
}

\begin{abstract}
${ }^{1}$ The assertions made in this paragraph are supported with detailed data in the section below entitled "The Outlook for Poverty and Joblessness in the Era of Welfare Reform." The poverty data cited in this Introduction are from the official poverty data for 2007, downloaded from http://www.census.gov/hhes/www/poverty/poverty07.htm, on $12 / 4 / 08$.
\end{abstract}

${ }^{2}$ Transitional Jobs programs have shown more limited long-term results in large part due to the inherent design of such programs as being 'transitional' in nature. However, other factors have affected the impact of the model. These include the following: 1 . Studies to date were on a rapidly emerging model and innovations in TJ programs over the past 5 years since most of the research was completed have strengthened the model; 2 . Funding sources to date for TJ have typically not provided adequate funds for the back end services - placement, retention, reemployment, and linkages to education and training and consequently, these funding restrictions have meant that many people were not able to stay in TJ long enough before their transition into unsubsidized employment; and, 3 . We believe that strong back end services are key to sustaining outcomes. Some programs, most notably the Center for Employment Opportunities, have changed this portion of the model dramatically in recent years with positive results.

${ }^{3}$ There is a large and consistent body of evidence supporting this point. See Devere's (2001) survey covering more than 50 studies in 39 states; Ac and Loprest (2001), p.vi; Danziger et al. (2002), using the rich data set from Michigan collected under the Women's Employment Study; Meyer and Cancian (2001), p.2, on the results of Wisconsin's welfare reform; and Bavier (2002), (2003)) using the SIPP data to track welfare leavers for a minimum of two years after exit.

${ }^{4}$ See, e.g., Economic Report of the President (2002), Table B-42, "Civilian Unemployment Rate, 1955-2001," p. 370. The rates for women and blacks fell to $4.1 \%$ and $7.6 \%$, respectively.

${ }^{5}$ See, U.S. Department of Labor (retrieved from http://www.bls.gov/news.release/empsit.nr0.htmon April 2, 2010).

${ }^{6}$ Solow (1998) is based on his Tanner Lectures given in 1996 and 1997, long before the results on welfare leavers we have cited became available.

7 'Hard-to-employ' is the term used by the Department of Labor and the Department of Health and Human Services to refer to recipients that are long-term welfare recipients who have two of three specified barriers to employment:

(1) holds no high school diploma or GED and has low reading or math skills, (2) requires substance abuse treatment for employment, or (3) has a poor work history.

${ }^{8}$ See National Transitional Jobs Network, What are Transitional Jobs. http://www.heartlandalliance.org/ntjn/about-transitional-jobs.html

${ }^{9}$ In addition to current welfare recipients, TJ programs also target recently released offenders, youth, refugees, people with disabilities, and other low-income workers.

${ }^{10}$ See National Transitional Jobs Network (2007). Basic Transitional Job Program Design; Downloaded from: http://www.transitionaljobs.net/About\%20TJ/47011_Basic_gp3.pdf

${ }^{11}$ We made these (admittedly rough) calculations per participant from Perez-Johnson et al. (2002), using total costs for Outreach/Recruitment in Table II.2 and the number of "Ever Active" participants in Table II.3. 
${ }^{12}$ The full text of the Workforce Investment Act of 1998, and subsequent amendments, can be found at: http://www.doleta.gov/USWORKFORCE/WIA/act.cfm

${ }^{13}$ Other organizations, such as nonprofit faith-based and community organizations, could also refer participants who have been unable to secure and maintain full-time stable employment due to the factors we described above (i.e. personal barriers to employment or insufficient labor market demand). We anticipate that such individuals would have first attempted to secure employment through the aforementioned avenues (e.g. public departments of social services, One-Stop Centers, etc.)

${ }^{14}$ Michalopoulos (2004), p.10. The studies behind this survey article used random assignment and found significant impacts on such "long-run" employment measures as "employed in year 1and 6 of 8 subsequent quarters," or "employment in 9 of 12 quarters."

${ }^{15}$ See his Table 3.4, p.63. In describing the duration and properties of the various programs, we rely primarily on the detailed descriptions of each program in the appendix of Perez-Johnson et al. (2002), pp. A.3-A.34. The duration data described in this study are broadly consistent with, but sometimes different from, statistics reported in Fraker et al. (2004) on the actual time spent by successful job seekers in Job Readiness Training and Job Search Assistance; for these data see Exhibit III.6 on p.57.

${ }^{16}$ See Fraker et al. (2004). Exhibit IV.3, "Percentage of WtW Enrollees Employed Sometime During the First and Second Years After Program Entry" (p.77) and Exhibit IV.13, "Percentage of WtW Enrollees Satisfying the TANF $30 \mathrm{Hrs} / \mathrm{Wk}$. Work Requirement One and Two Years After Program Entry" (p.83), present the relevant data.

${ }^{17}$ See Perez-Johnson et al. (2002), Figure III.4 (p.40) for costs per participant of the various components of each of the 18 programs studied; for the costs for our Phase II we used the estimates for two components: "Job-

Readiness/Case Management" and "Job Development/Placement." See footnote 29, above, for our sources of data on the duration of each component in each of the 18 programs.

${ }^{18}$ For example, a POJ participant can be 'suspended' for one-month after which he/she can reapply. Subsequent issues with meeting participation standards can result in longer 'suspensions'.

${ }^{19}$ For the 18 programs studied in Perez-Johnson et al. (2002), we calculated that Administrative costs ranged from $\$ 85$ to $\$ 604$ per participant. We took total Administrative costs in Table II.2 (p.19) and divided them by the number of "Ever Active" participants for the given year in Table II.3 (p. 23).

${ }^{20}$ In most cases, the wage rate was set at or below the minimum wage in order to encourage program participants to actively seek higher paying jobs in the private sector.

${ }^{21}$ See U.S. Department of Health and Human Services (2008). Downloaded 9/11/2008 from: www.acf.hhs.gov/programs/ ofa/data-reports/caseloard/2007 etc.

${ }^{22}$ See Gibbs et al. (2004), pp. 2-8 through 2-11 and, especially, Table 2.2 on p.2-10.

${ }^{23}$ We realize that it is controversial to propose providing jobs for non-citizen immigrants. We consider this case on the grounds of providing equal opportunity for children and reducing child poverty, but we consider also an alternative that excludes for POJ all adults from child-only cases. .

${ }^{24}$ No direct estimates exist of the number of TANF recipients below the poverty line, as far as we can tell, but the stringent TANF eligibility criteria suggest that a reasonable assumption is that all TANF recipients, except, possible, a percentage of child-only cases, fell below the poverty line. Data for 1996, used for a scenario we "run" in the next section, show that all recipients existing on 1996 AFDC benefits plus food stamps fell below the poverty line (U.S. House of Representatives, Committee on Ways and Means (1998), Table 7-8, pp. 416-418).

${ }^{25}$ Using the 2007 poverty thresholds by size of family, a full-time, minimum wage job under POJ plus food stamps and the EITC would raise all families above the poverty line except for those with 5 or more children. Since we 
could find out the number of families in this category (just under 43,000), but not the total number of children, in order to calculate the number of children we assumed six children on average per family in this class, a total of approximately 255,000 children. The same procedure was used to make the calculations for 1996. 